\title{
Dynamic characteristics of adsorbed monolayers of 1-dodecanethiol on gold (111) terraces from in-situ scanning tunneling microscopy imaging
}

\author{
F. Terán Arce, M.E. Vela, R.C. Salvarezza, A.J. Arvia* \\ Instituto de Investigaciones Fisicoquimicas Teóricas y Aplicadas (INIFTA), Sucursal 4, Casilla de Correo 16, 1900 La Plata, \\ Argentina
}

Received 17 October 1997; received in revised form 22 December 1997

\begin{abstract}
The dynamics of 1-dodecanethiol self-assembled monolayers (SAMs) on Au(111) produced by contacting pure thiol was followed by in situ STM at $298 \mathrm{~K}$. Initially, these SAMs constituted a heterogeneous surface consisting of disordered and ordered adsorbate domains at terraces, step edges and pits, forming a $\mathrm{p}(6 \times 1)$ superlattice which later changed to the $(\sqrt{3} \times \sqrt{3}) \mathrm{R} 30^{\circ}$ structure. Subsequently, the $\mathrm{c}(4 \times 2)$ superlattice was also observed. Surface dynamics involves the coalescence and Ostwald ripening phenomena at pits occurring simultaneously with adsorbate ordering at different surface domains. The difference in surface mobility between adsorbate-free and 1dodecanethiol-covered $\mathrm{Au}(111)$ can be explained taking into account both gold lattice relaxation due to adsorption and alkyl chain interaction at SAM. Data analysis in terms of clustering theory allowed us to conclude that a single mechanism is likely involved in the overall surface phenomena in which the mass transport is either a nonsteady state surface diffusion or an interface transfer along step edges as rate-determining step. (C) 1998 Elsevier Science Ltd. All rights reserved.
\end{abstract}

Keywords: Adsorbate STM imaging on $\mathrm{Au}(111)$; 1-dodecanethiol adsorbate structure; SAMs dynamics; Clustering theory application

\section{Introduction}

Over the past few years self-assembled monolayers (SAMs) of alkanethiol molecules particularly on Au [1], as well as on other metals such as $\mathrm{Ag}$ and $\mathrm{Ni}[2,3]$, have attracted massive interest in the theoretical aspects of charge transfer processes at complex electrochemical interfaces and have been widely applied to processes such as in corrosion protection, tribology, anchoring of macromolecules and biosensing [4,5]. Accordingly, alkanethiol SAMs have been extensively studied by several techniques related to contact angle measurements [6], ellipsometry [7], Fourier transform infrared spectroscopy, electrochemistry [7-9], grazing X-ray diffraction [10], He diffraction [11], second

\footnotetext{
* Corresponding author.
}

harmonic generation [12], scanning probe microscopies [13], near edge X-ray absorption fine structure (NEXAFS) and ultraviolet photoemission spectroscopy [14], and nuclear magnetic resonance [15]. In general, the most commonly used procedure for preparing thiol SAMs has been the immersion of a clean gold substrate into a $1 \mathrm{mM}$ thiol ethanolic solution for about $24 \mathrm{~h}$ [4]. For these SAM preparations, alkanethiol adsorption from the vapor phase either in air or in ultra high vacuum (UHV) [16, 17], and immersion in pure liquid thiol [18] have also been proposed, although less frequently employed, particularly the latter procedure. Alkanethiol multilayers have also been produced on $\mathrm{Au}(111)$ and HOPG for longer thiol/ substrate contact times followed by solvent evaporation [19, 20].

From the structural standpoint, alkanethiol SAMs on $\mathrm{Au}(111)$ have been described as a $(\sqrt{3} \times \sqrt{3}) \mathrm{R} 30^{\circ}$ 
commensurate structure, with the alkyl chains totally extended in an all trans configuration, the axis of each molecule being tilted about $30^{\circ}$ with respect to the surface normal [1]. The alkyl chains also exhibit a twist angle of about $52^{\circ}$ defined by the zig-zag of the carbon atom structure in the chain [1]. At $100 \mathrm{~K}$ the alkyl chain spacing is $d=0.5 \mathrm{~nm}$, but as the temperature is increased the chain ordering gradually disappears due to thermal vibrations [21].

Ab-initio calculations for the alkanethiolate-gold bonding [22] have shown that hollow sites, involving a second-layer gold atom located directly below the sulphur atom from the thiol molecule, are the most stable sites for adsorption on $\mathrm{Au}(111)$. This type of bonding would imply a mixed $\sigma$ and $\pi$ bonding character with a dominating contribution of the latter. The corresponding adsorption energy difference between hollow and top adsorption sites is about $25 \mathrm{~kJ} / \mathrm{mol}$, a figure which is one order of magnitude greater than the thermal energy at $298 \mathrm{~K}$. From these calculations it has been concluded that the angle between $\mathrm{Au}(111)$ and the $\mathrm{S}-\mathrm{C}$ bond is about $180^{\circ}$ for the $\mathrm{S}$ atom sp hybridization, and about $110^{\circ}$ for the $\mathrm{S}$ atom $\mathrm{sp}^{3}$ hybridization. Correspondingly, the $\mathrm{Au}(111)-\mathrm{S}$ and $\mathrm{S}-\mathrm{C}$ bond distances are 0.1826 and $0.1905 \mathrm{~nm}$ in the former case, and 0.1817 and $0.1936 \mathrm{~nm}$ in the latter. The polar component of the $\mathrm{Au}(111)-\mathrm{S}$ bond involves a fraction of 0.25 of the electronic charge distributed on the $\mathrm{S}$ atom. Then, the most accepted picture for alkanethiol chemisorption on gold corresponds to that of a surface thiolate represented by $\mathrm{X}\left(\mathrm{CH}_{2}\right) \mathrm{S}^{-}-\mathrm{Au}{ }^{+}$[14], where the thiolate-gold bond energy is estimated as $184 \mathrm{~kJ} /$ mol [23]. Nevertheless, it has recently been found that alkanethiol molecules on $\mathrm{Au}(111)$ are adsorbed on a mixed bridge and hollow site configuration, rather than on a single hollow site configuration [24].

Although most of the work has been directed towards alkanethiol SAM structural characterization, little work has been undertaken to understand the formation mechanism and dynamics of these SAMs on well defined surfaces. Kinetic studies have focused mainly on the nucleation and growth of SAMs themselves rather than on structural changes including those of the substrate surface. For Au(111), STM imaging has shown that the formation of alkanethiol adlayers involves the formation of pits, most of them being one gold atom in depth [25]. The nature of these pits is not completely understood. It has been argued that these pits are due to an etching process at the substrate [26], whereas other explanations have attributed their origin to a break of balance in the lateral pressure of the gold surface caused by the adsorbed species [27]. More recently [28], from STM imaging data under UHV condition it has been suggested that $\mathrm{Au}$ atoms are forced out of the surface layer by relaxation of the compressed $\mathrm{Au}(111)$ herringbone struc- ture, thereby originating pits. STM data have also shown that mass transport by surface diffusion occurs at alkanethiol adlayers on $\mathrm{Au}(111)$, and the corresponding surface diffusion rates have been measured $[29,30]$.

Different domains at the SAM level can be also observed [31] by using high tunneling resistances. Certain domains exhibit a $(\sqrt{3} \times \sqrt{3}) \mathrm{R} 30^{\circ}$ lattice while others show superstructures of this lattice with a $c(4 \times 2)$ superlattice as the most common one. The origin of this superlattice has been interpreted in various ways, as due to different twist angles of the alkyl chains [32], disulfide formation [33], and the existence of distinguishable adsorption sites [34]. More recently, it has been found that these domains undergo structural transitions [35], and a possible mechanism linking the mobility of the $\mathrm{Au}(111)$ substrate with the dynamics of these domains has been suggested [33].

This work describes the dynamics of 1-dodecanethiol monolayers adsorbed on $\mathrm{Au}(111)$ terraces from pure liquid thiol followed by in-situ STM imaging. Initially, the heterogeneous adlayer consists of disordered and ordered domains coexisting with monoatomic depth pits in the substrate which are also adsorbate covered. After keeping the substrate in contact with thiol for 1 $\mathrm{h}$, the change of disordered domains into ordered domains can be observed. In this case, the final structure approaches the SAM structure resulting after a 24 $\mathrm{h}$ substrate immersion in $1 \mathrm{mM}$ thiol methanolic solution [36,37]. The kinetics of pit displacement at terraces and their coalescence can be explained by a mass transport involving the gold-alkyl thiolate as the mobile species, in which either a nonsteady state surface diffusion or an interface transfer along pit borders is the rate determining step.

\section{Experimental}

Nanoscope III STM equipment (Digital Instruments, Santa Barbara CA) was employed. STM experiments were performed utilizing commercial $\mathrm{Pt}-\mathrm{Ir}$ tips (Digital Instruments, Santa Barbara, CA), and occasionally, Pt-Ir tips snipped with wire cutters. When necessary, to correct for tilt and bow, images were plane removed and flattened utilizing the image processing software of the instrument. This software was also used to measure the pit size resulting from STM images.

In-situ STM experiments were performed in a liquid cell. After a region for imaging had been located, about $50 \mu \mathrm{l}$ of pure 1-dodecanethiol (Fluka) were put on the Au substrate while the tip was scanning the surface under an applied bias potential. Since 1-dodecanethiol is nonconductive, the possibility of any electrochemical reactions under these conditions 
should be discarded. The absence of faradaic currents was confirmed by using low tunneling currents. Typical values used for bias voltage were in the range $1.5 \mathrm{~V} \leq E_{\mathrm{b}} \leq 2.5 \mathrm{~V}$, and tunneling currents covered the range $100 \mathrm{pA} \leq i_{\mathrm{T}} \leq 150 \mathrm{pA}$.

Ex-situ AFM images were performed with silicon nitride tips with a cantilever constant of $0.12 \mathrm{nN} / \mathrm{m}$ under the contact mode and applying different forces in the range $65 \mathrm{nN} \leq F \leq 260 \mathrm{nN}$.

Gold films evaporated on glass $(250 \mathrm{~nm}$ thick gold layer onto 'Robax' glass, AF Berliner glass $\mathrm{KG}$, Germany) with a $2 \mathrm{~nm}$ thick chromium undercoating for better adhesion to the glass surface were used as substrates. In order to obtain large $\mathrm{Au}(111)$ terraces, these substrates were flame annealed [38]. Before each experiment those substrates which had not being used immediately after their preparation, were immersed for about $3 \mathrm{~min}$ in a $70 \% \quad \mathrm{H}_{2} \mathrm{SO}_{4}+30 \% \quad \mathrm{H}_{2} \mathrm{O}_{2}$ solution for additional cleaning. Occasionally, this procedure led to pit formation, as has been observed for $\mathrm{Au}(111)$ after immersion in either thiol-containing solutions [39,40], or sulfochromic acid [41], as well as from oxidation-reduction cycles in acid solutions $[38,42]$.
Substrates employed in this work were characterized in air by AFM and STM. All runs were made at $298 \mathrm{~K}$.

\section{Results and interpretation}

\subsection{Structure and formation of domains}

The ex-situ STM image of the adsorbate-free Au substrate (Fig. 1a) shows wide terraces with step borders forming $60^{\circ}$ angles which are characteristic of the $\mathrm{Au}(111)$ surface. Monatomic steps $0.243 \mathrm{~nm}$ in depth separating $\mathrm{Au}(111)$ planes [43] can also be seen. High resolution images at substrate terraces reveal the hexagonal $\mathrm{Au}$ (111) lattice with the nearest neighbor distance $d=0.289 \mathrm{~nm}$ (Fig. 1b).

The ex-situ STM image of the $\mathrm{Au}(111)$ substrate (Fig. 2a) obtained immediately before adding pure dodecanethiol also exhibits randomly distributed pits $3.0 \mathrm{~nm}$ in average diameter and $0.243 \mathrm{~nm}$ in step height. These pits are specific to the clean $\mathrm{Au}(111)$ substrate. Otherwise, the in-situ STM image obtained for the same substrate area after being in contact with a)

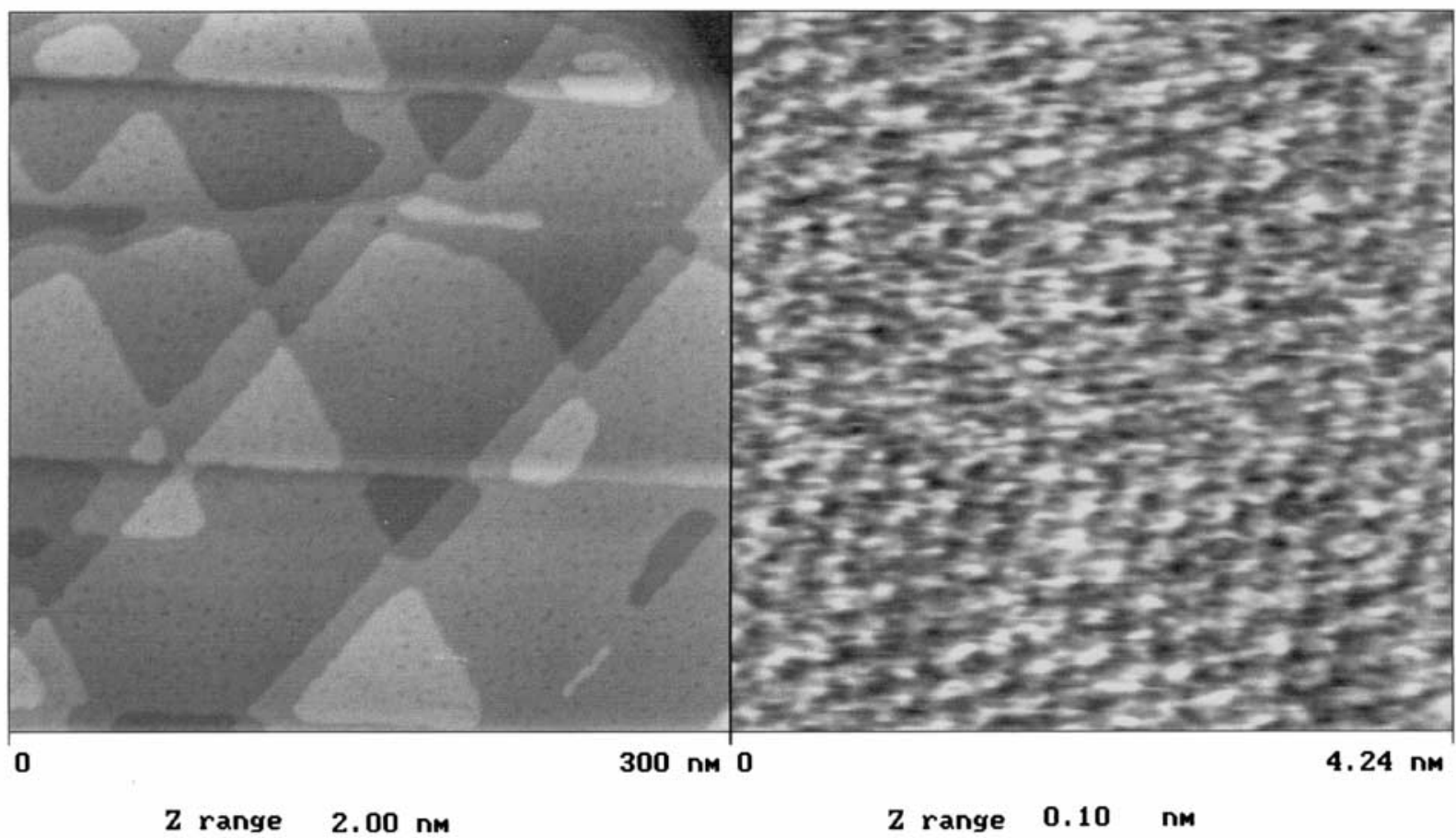

Fig. 1. (a) Ex-situ STM image $\left(300 \times 300 \mathrm{~nm}^{2}\right)$ showing terraces of the gold substrate. (b) Higher resolution ex-situ AFM image $\left(4.24 \times 4.24 \mathrm{~nm}^{2}\right.$, raw data) of a gold terrace. The hexagonal lattice with the nearest neighbor distance of $\mathrm{Au}(111)$ lattice $(d=0.29$ $\mathrm{nm})$ can be observed. 
a)

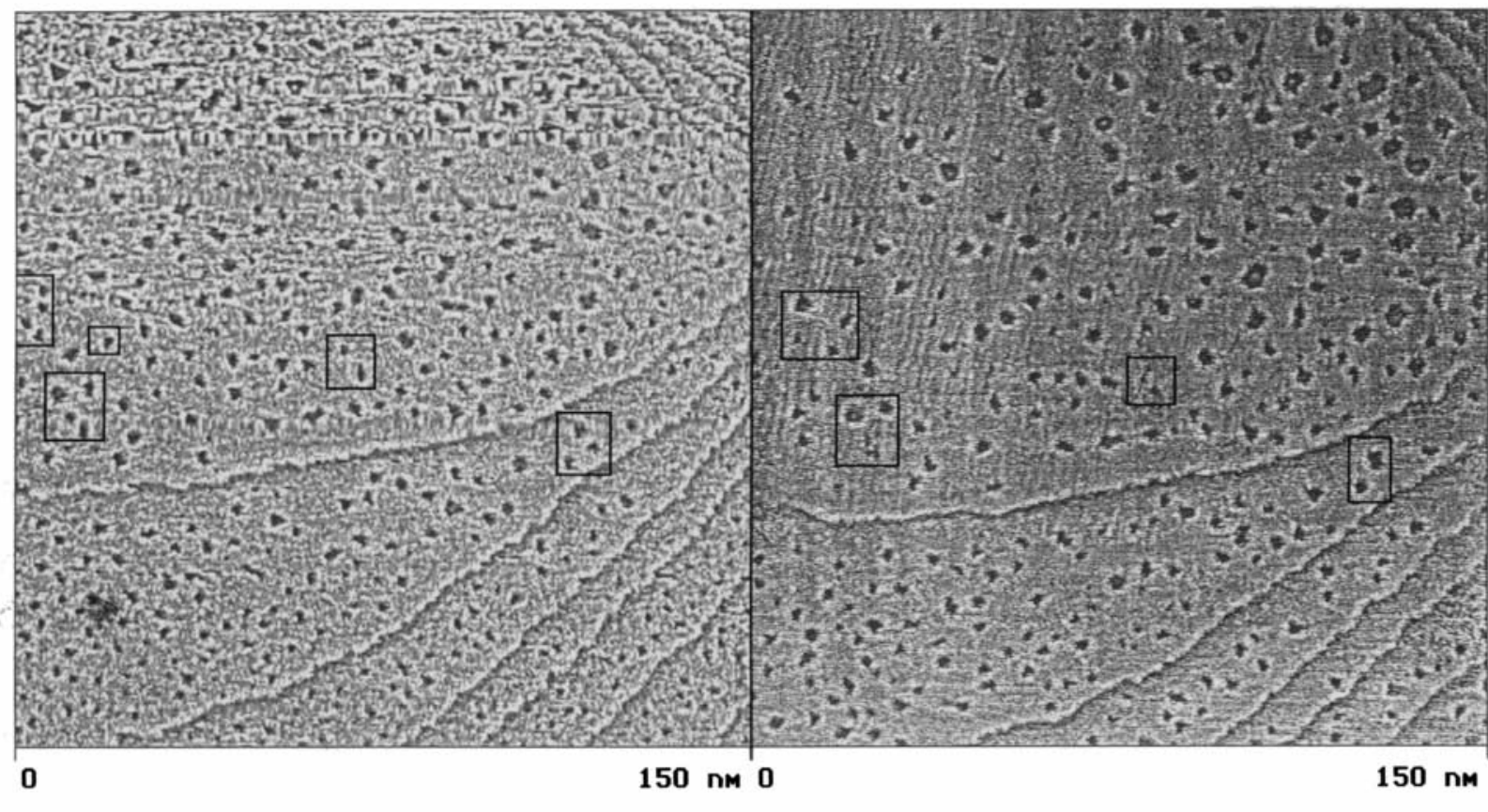

$\mathrm{Z}$ range

$0.500 \mathrm{~nm}$

Fig. 2. Comparable STM images $\left(150 \times 150 \mathrm{~nm}^{2}\right)$. (a) Initial (ex-situ) gold substrate before 1-dodecanethiol addition. (b) STM image (in-situ) of the same surface region depicted in (a) after $5 \mathrm{~min} 42 \mathrm{~s}$. Marked squares helps the reader follow the changes of pit morphology described in the text. For this STM image the contrast was adjusted to enhance the adsorbate striped pattern and pits.

1-dodecanethiol for $t=5 \mathrm{~min} 42 \mathrm{~s}$ (Fig. 2b) shows changes in the average size and distribution of pits (see Fig. 2b, squared areas). These changes indicate a certain dynamics involving both the adlayer and the substrate. The appearance of a striped pattern at pit-free surface domains can also be observed. These stripes exhibit a $0.1 \mathrm{~nm}$ corrugation and are aligned parallel to each other (see upper left hand side of Fig. 2b).

High resolution in-situ STM images at interstripe regions (Fig. 3a) contain a hexagonal $(\sqrt{3} \times \sqrt{3}) \mathrm{R} 30^{\circ}$ lattice with the nearest neighbor distance $d=0.5 \mathrm{~nm}$, and a stripe-to-stripe separation which is sixfold the value of $d$ for the hexagonal lattice, thus resulting in a $\mathrm{p}(6 \times 1)$ superstructure of the thiol adlattice. A scheme of the aforementioned description of the thiol adlayer is depicted in Fig. 3b, where large circles in A (B) rows correspond to those thiol molecules appearing in lower (higher) contrast in the STM image and being adsorbed at hollow sites with hcp (fcc) stacking sequence [36, 37].

The striped adlayer structure (Fig. 4a) undergoes a change to the $(\sqrt{3} \times \sqrt{3}) \mathrm{R} 30^{\circ}$ structure, which probably is the most stable adlayer configuration (Fig. 4b), and this change is accompanied by the appearance of new pits (see squared areas in Fig. 4b). Finally, the morphology of the thiol adlayer, as seen by in-situ STM for 1-3 h exposure to 1-dodecanethiol (Fig. 5a and $b$ ), shows domains with a structure closely resembling those structures found when thiol SAMs were prepared from $1 \mathrm{mM}$ thiol methanolic solutions after a $24 \mathrm{~h}$ immersion time [44]. At this stage the $\mathrm{c}(4 \times 2)$ superlattice can still be observed at the 1-dodecanethiol monolayer level (Fig. 5b). In fact, reversible transitions between the $(\sqrt{3} \times \sqrt{3}) \mathrm{R} 30^{\circ}$ lattice and the $\mathrm{c}(4 \times 2)$ superlattice take place when the interaction between $\mathrm{Au}(111)$ and 1-dodecanethiol solution extends for 1-4 h [33].

\section{2. $S T M$ and AFM images}

Both AFM and STM images for dodecanethiol adlayers obtained in this work confirm the $(\sqrt{3} \times \sqrt{3}) \mathrm{R} 30^{\circ}$ structure previously reported $[45,46]$. While STM images obtained at high tunneling resistances exhibit $\mathrm{p}(6 \times 1)$ and $\mathrm{c}(4 \times 2)$ superstructures, AFM images obtained in air with $F \cong 65 \mathrm{nN}$ show only the $(\sqrt{3} \times \sqrt{3}) \mathrm{R} 30^{\circ}$ structure (Fig. 6a). However, as reported earlier [47], as the value of $F$ is increased the adlayer structure becomes gradually disordered (Fig. 6b), and finally, for $F \cong 260 \mathrm{nN}$ the displacement 
a)
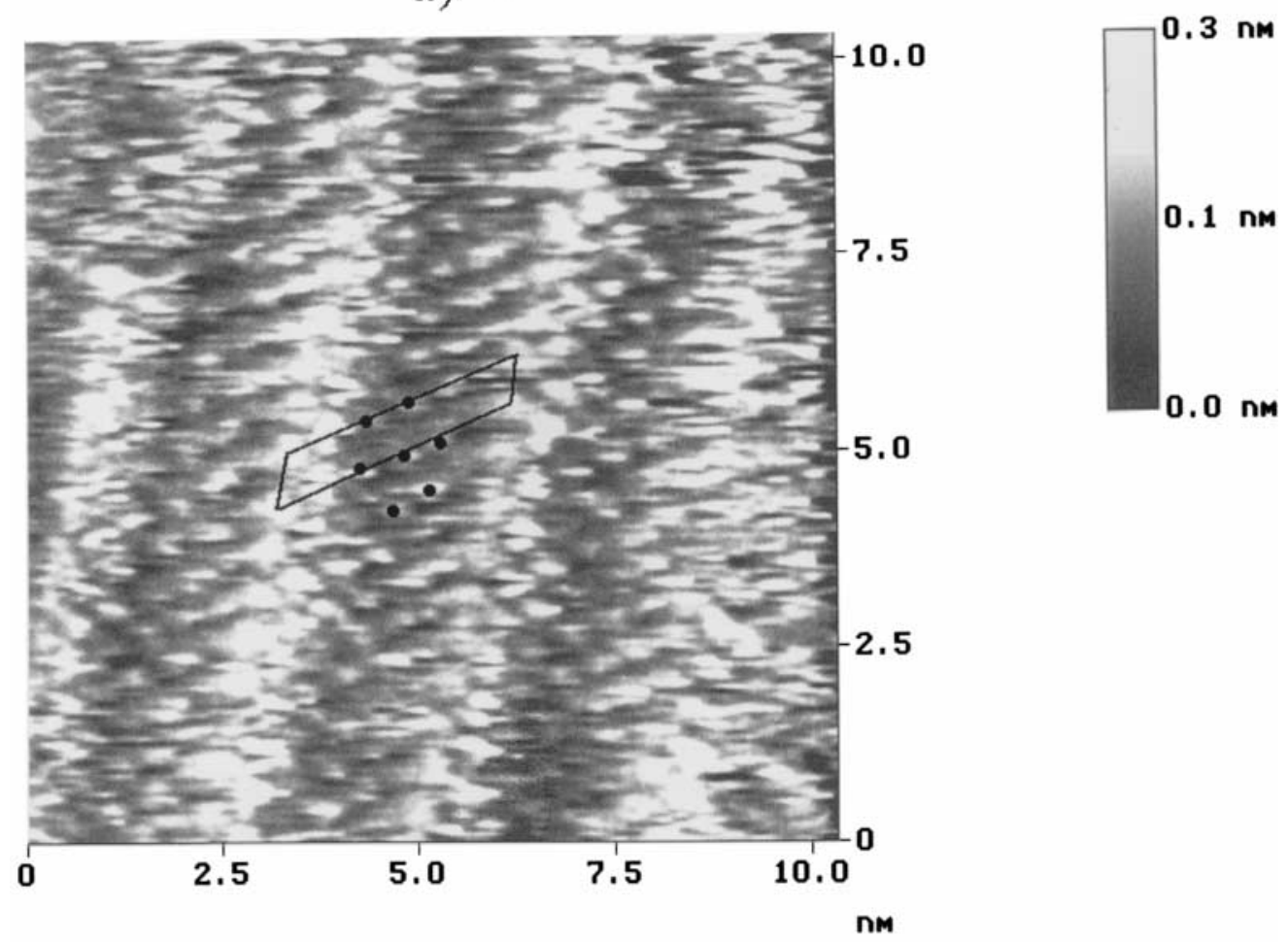

b)

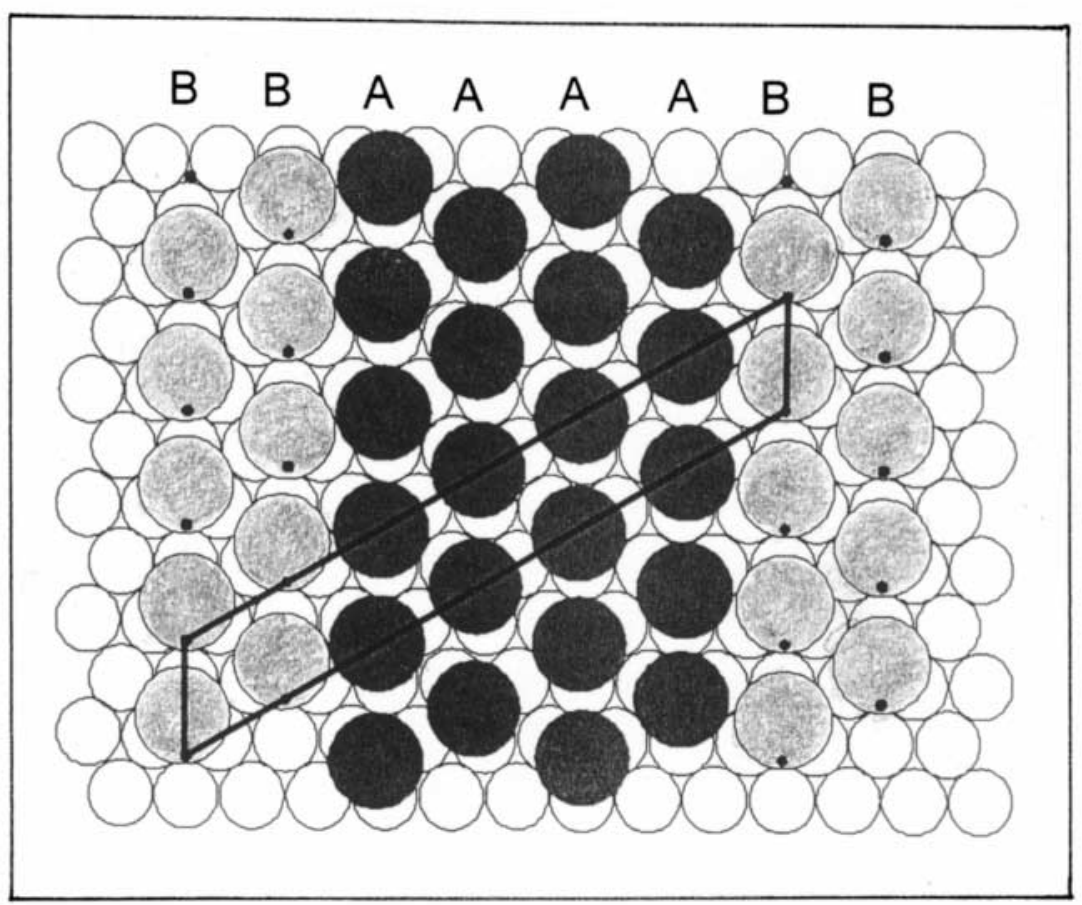

Fig. 3. (Caption overleaf). 
a)

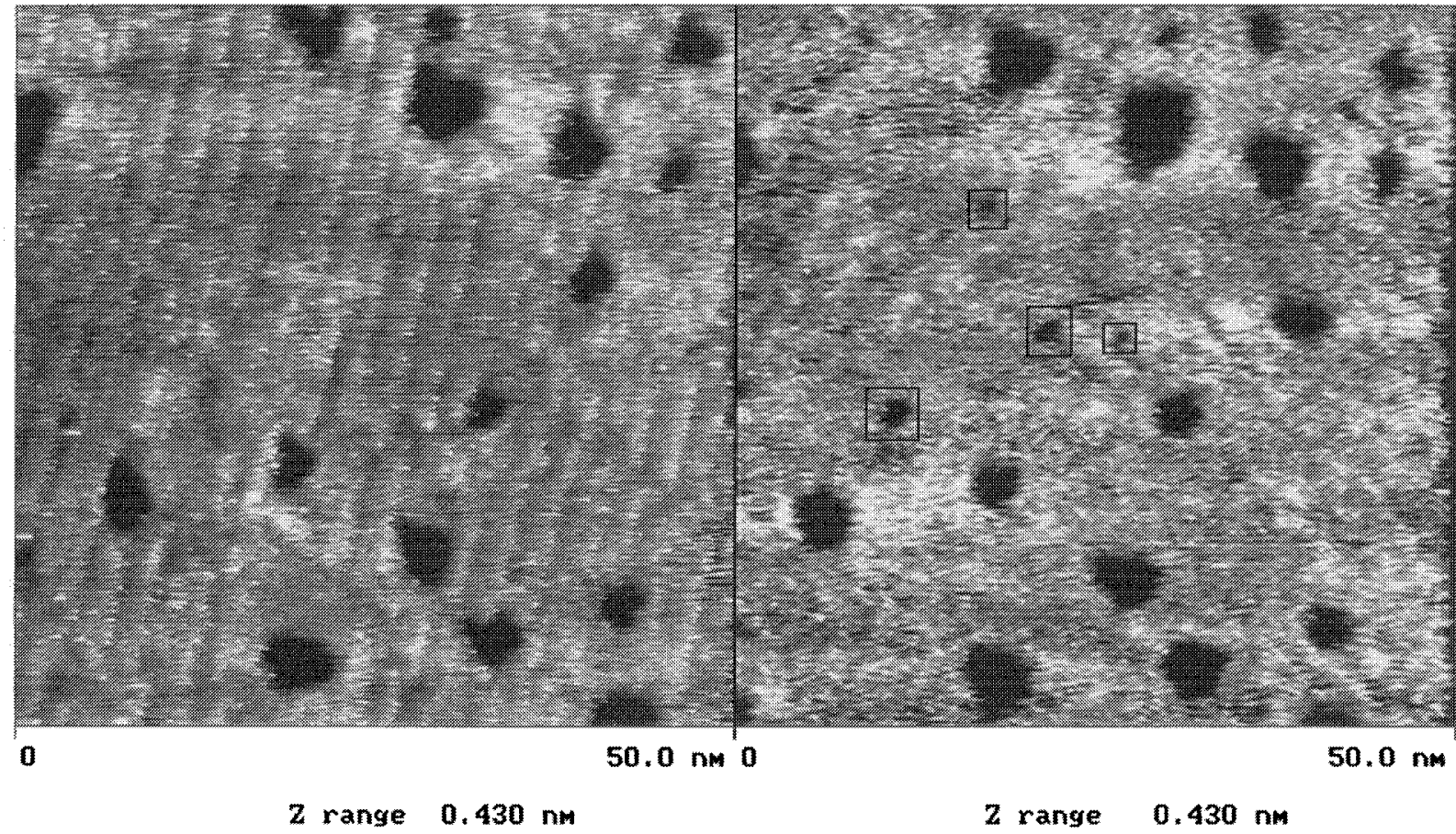

Fig. 4. Sequence of in-situ STM images $\left(50 \times 50 \mathrm{~nm}^{2}\right)$ showing the dynamic behavior of the 1-dodecanethiol adlayer on Au(111). (a) Prevalence of the $\mathrm{p}(6 \times 1)$ striped structure after $t=5 \mathrm{~min} 42 \mathrm{~s}$ can be observed. (b) The same region $t>9$ min exhibits the $(\sqrt{3} \times \sqrt{3}) \mathrm{R} 30^{\circ}$ structure and the appearance of new pits (square marked).

of adsorbed thiol molecules from the substrate surface can definitely be observed (Fig. 6c). The structure of the clean substrate can be clearly seen in Fig. 6d which exhibits the typical nearest neighbor distance of $\mathrm{Au}(111), d=0.29 \mathrm{~nm}$, and a $30^{\circ}$ angle rotation with respect to the aligned 1-dodecanethiol layer (compare Fig. 6e and f). It should be noted that the value of $F$ required for displacing the thiol monolayer varies with the tip radius [48], and that STM senses the sulphur heads of the thiol molecules, whereas AFM probes the alkyl tails of the molecules interacting with the AFM tip.

\subsection{Surface mobility}

Sequential STM images $\left(150 \times 150 \mathrm{~nm}^{2}\right)$ of the $\mathrm{Au}(111)$ surface for different contact times with 1dodecanethiol (Fig. 7) show changes in pit size, and their coalescence either at terraces or step edges. Thus, for $t=9 \min 6 \mathrm{~s}$ (Fig. 7a) the pit 1-to-step edge and pit 2-to-step edge distances measured along the $x$-direction are 6.4 and $8.2 \mathrm{~nm}$, respectively, and for $t=17 \mathrm{~min} 27 \mathrm{~s}$ later (Fig. 7b), those distances decrease to 4.7 and $6.7 \mathrm{~nm}$, respectively. Subsequently (Fig. 7c, $t=21 \mathrm{~min} 54 \mathrm{~s}$ ), pit 1 disappears becoming a part of the step edge and pit 2 remains at $6.3 \mathrm{~nm}$ from the step edge. Finally (Fig. 7d, $t=30 \min 12 \mathrm{~s}$ ), pit 2 also disappears at the step edge. Furthermore, the nearest neighbor pit separation (see squared area 3 in Fig. $7 \mathrm{~b}$ ) is ca. $5.6 \mathrm{~nm}$, the radius of the largest pit is $7.6 \mathrm{~nm}$, and that of the smallest one is $2.95 \mathrm{~nm}$, and for $t=30 \mathrm{~min} 12 \mathrm{~s}$ (Fig. 7d), both pits merge together forming a single larger pit $9.1 \mathrm{~nm}$ in average radius. From these results one can conclude that on increasing the contact time the average size of pits tends to increase.

From the evolution of pits followed by sequential STM imaging, it is possible to estimate an average

Fig. 3. (a) In-situ STM image $\left(10 \times 10 \mathrm{~nm}^{2}\right)$ of 1-dodecanethiol adlayer on gold showing the striped structure and the molecular resolution in and between stripes. (b) A scheme of the structural model used for the interpretation of the STM image depicted in (a). Unfilled circles represent $\mathrm{Au}(111)$ atoms, dark circles (forming lines denoted by $\mathrm{A}$ ) correspond to $\mathrm{S}$ heads of thiol molecules located at hollow sites hep, and grey circles denote $\mathrm{S}$ heads of thiol molecules at hollow sites fcc (forming lines denoted by B). Lines B and A are assigned to higher and lower contrast spots at the STM image, respectively. Small black dots indicate hollow fcc adsorption sites at $\mathrm{Au}(111)$ surface. 

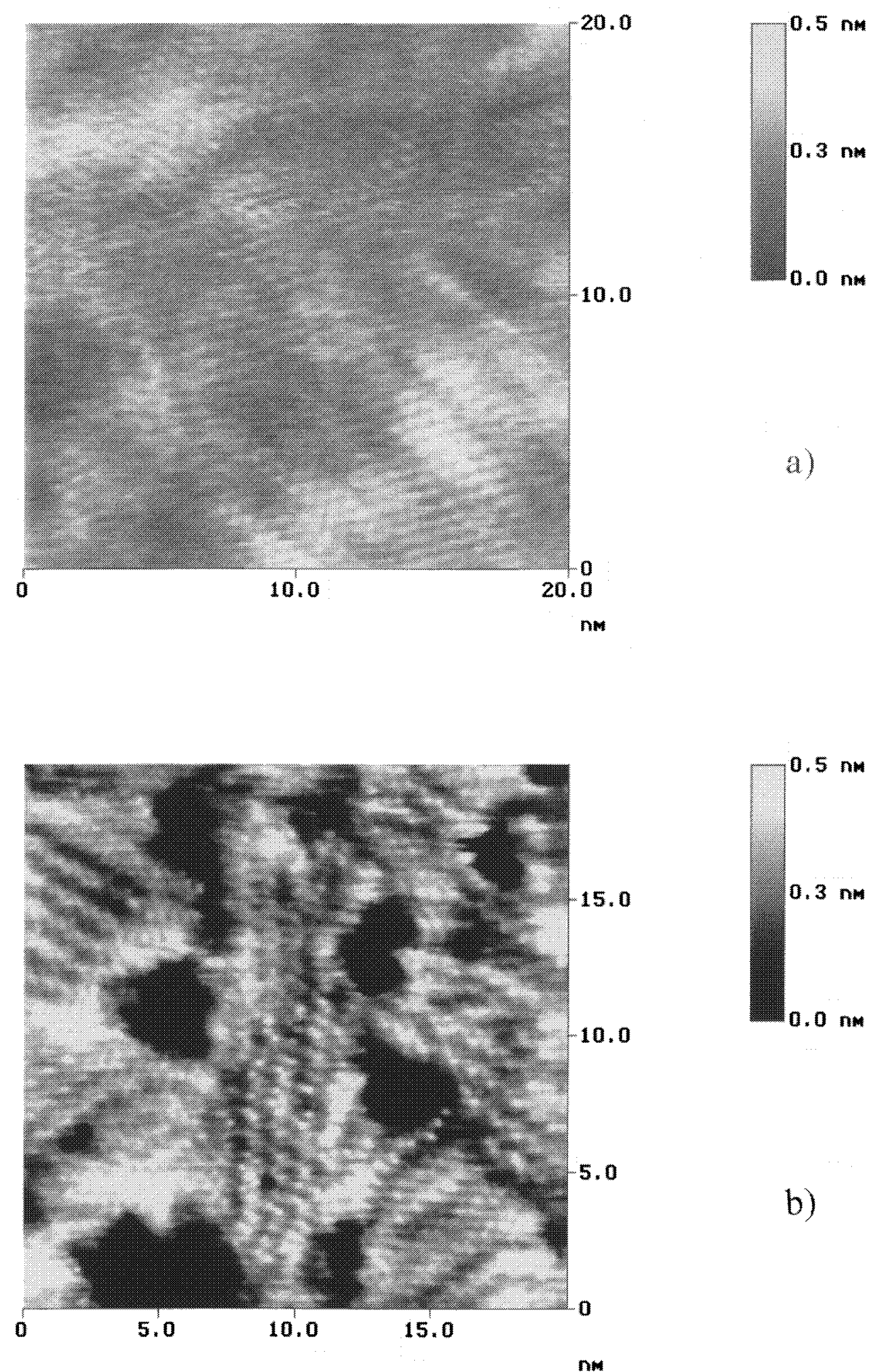

Fig. 5. In-situ STM images $\left(20 \times 20 \mathrm{~nm}^{2}\right)$ of $\mathrm{Au}(111)$ after a $1 \mathrm{~h}$ contact with 1-dodecanethiol in which the $(\sqrt{3} \times \sqrt{3}) \mathrm{R} 30^{\circ}$ (a), and $c(4 \times 2)(b)$ structures can be observed. 
a) $65 \mathrm{nN}$

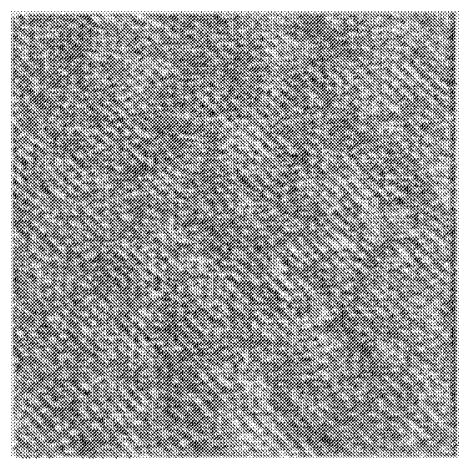

\section{d) $260 \mathrm{nN}$}

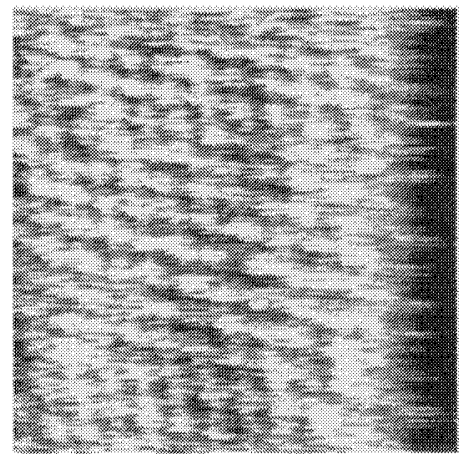

b) $195 \mathrm{nN}$

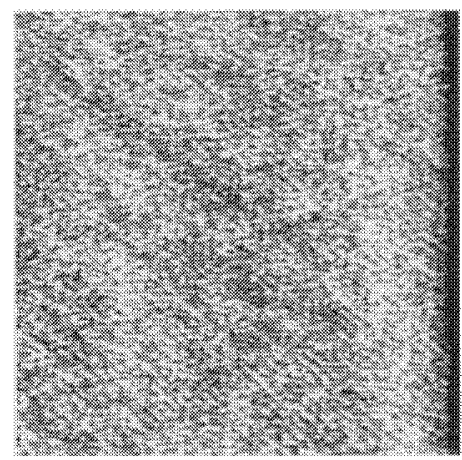

\section{e) $65 \mathrm{nN}$}

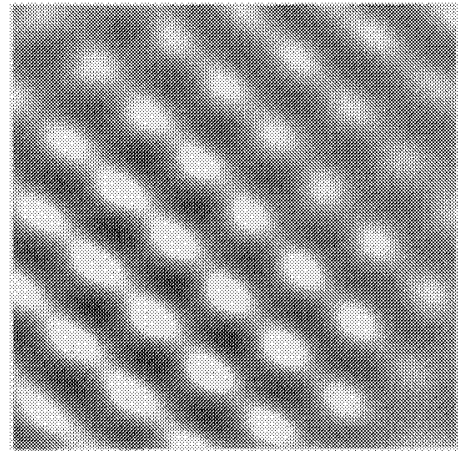

c) $260 \mathrm{nN}$

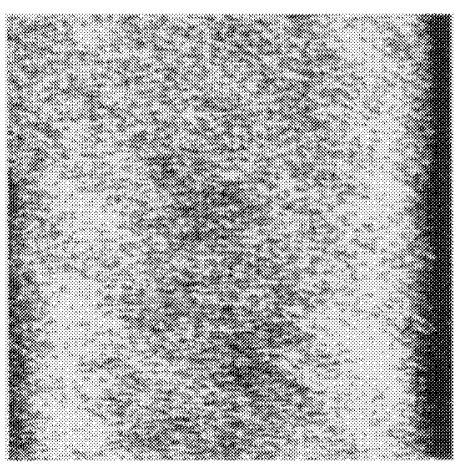

f) $260 \mathrm{nN}$

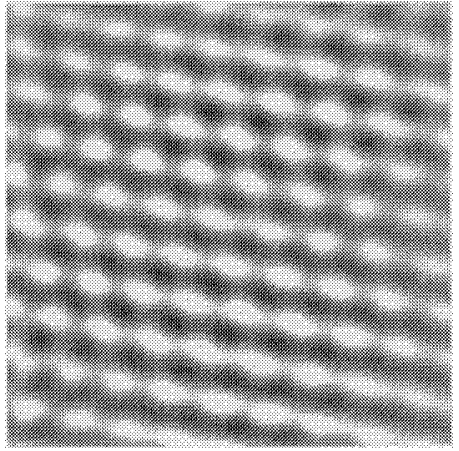

Fig. 6. Influence of the value of $F$ on the ex-situ AFM imaging (contact mode) for a 1-dodecanethiol adlayer on Au(111). (a) $F=65 \mathrm{nN}\left(20 \times 20 \mathrm{~nm}^{2}\right.$ image). (b) $F=195 \mathrm{nN}\left(20 \times 20 \mathrm{~nm}^{2}\right.$ image). (c) $F=260 \mathrm{nN}\left(20 \times 20 \mathrm{~nm}^{2}\right.$ image). (d) AFM image $\left(5 \times 5 \mathrm{~nm}^{2}\right.$, raw data) resulting from $F=260 \mathrm{nN}$ in which the hexagonal Au(111) lattice can be observed. (e) Zoomed AFM image $\left(2.75 \times 2.75 \mathrm{~nm}^{2}\right.$, filtered data) resulting from $F=65 \mathrm{nN}$ in which the 1-dodecanethiol adsorbate $(\sqrt{3} \times \sqrt{3}) \mathrm{R} 30^{\circ}$ structure can be observed. (f) Zoomed AFM $2.75 \times 2.75 \mathrm{~nm}^{2}$ filtered image from (d).

value of $D_{\mathrm{s}}(p)$, the surface diffusion of a single pit averaged from diffusing pits, from Einstein's relationship $D_{\mathrm{s}}(p)=\Delta x^{2} / 2 t$, where $\Delta x$ is the travelling distance of the pit center towards the step edge for time $t$. Thus, from the averaged slope of $\Delta x^{2}$ vs $t$ plots (Fig. 8a) it follows that $\left\langle D_{\mathrm{s}}(p)\right\rangle=(3 \pm 2) \times 10^{-17}$ $\mathrm{cm}^{2} / \mathrm{s}$.

On the other hand, from the time dependence of $\langle R\rangle$, the average pit radius, it would be possible to establish the likely mechanism controlling pit relaxation. For this purpose, experimental data derived from in-situ STM imaging were plotted according to the following equation (Fig. 8b):

$$
\langle R(t)\rangle \propto t^{x} .
$$

The $\langle R\rangle$ and $t$ scale involved in the experimental data makes the evaluation of exponent $x$ ambiguous, as values in the range $0.25 \leq x \leq 0.5$, which are expected from the clustering theory [49], are compatible with data dispersion. Therefore, by attempting to discriminate the likely mechanism of the process, the pit size distribution including a critical pit radius $R_{\mathrm{c}}$ can be considered.

The pit size distribution for the ripening process plotted as $N$, the number of pits vs the $R / R_{\mathrm{c}}$ ratio (Fig. 9) exhibits a maximum for $R / R_{\mathrm{c}}=\left(R / R_{\mathrm{c}}\right)_{\mathrm{M}}=1$. Furthermore, the full width at half maximum $\left(w_{1 / 2}\right)$ is close to 0.6. Finally, the pit size distribution function extends to $\left(R / R_{\mathrm{c}}\right)_{\text {lim }} \approx 1.65$. Then, the analysis of the pit size distribution function provides information for discussing the probable ripening and pit coalescence mechanism.

\section{Discussion}

4.1. Formation and dynamics of the 1-dodecanethiol monolayer on $\mathrm{Au}(111)$

Results from this work show that the interaction between 1-dodecanethiol and $\mathrm{Au}(111)$ terrace sites produces a heterogeneous adlayer consisting of different 

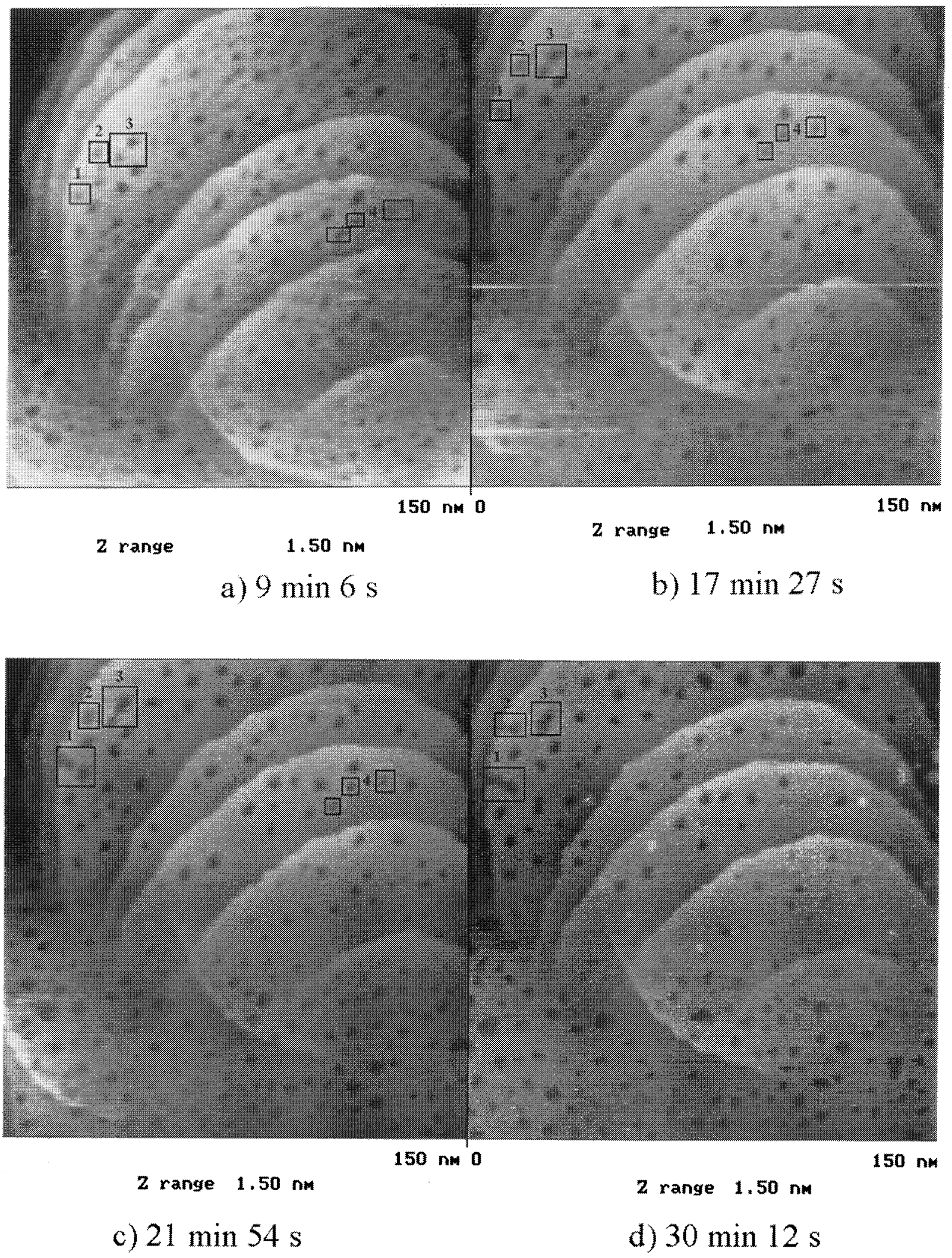

Fig. 7. Sequential in-situ STM images $\left(150 \times 150 \mathrm{~nm}^{2}\right)$ of $\mathrm{Au}(111)$ in contact with 1-dodecanethiol where changes in pit morphology can be followed (see numbered squares). A full description of this figure is given in the text. 

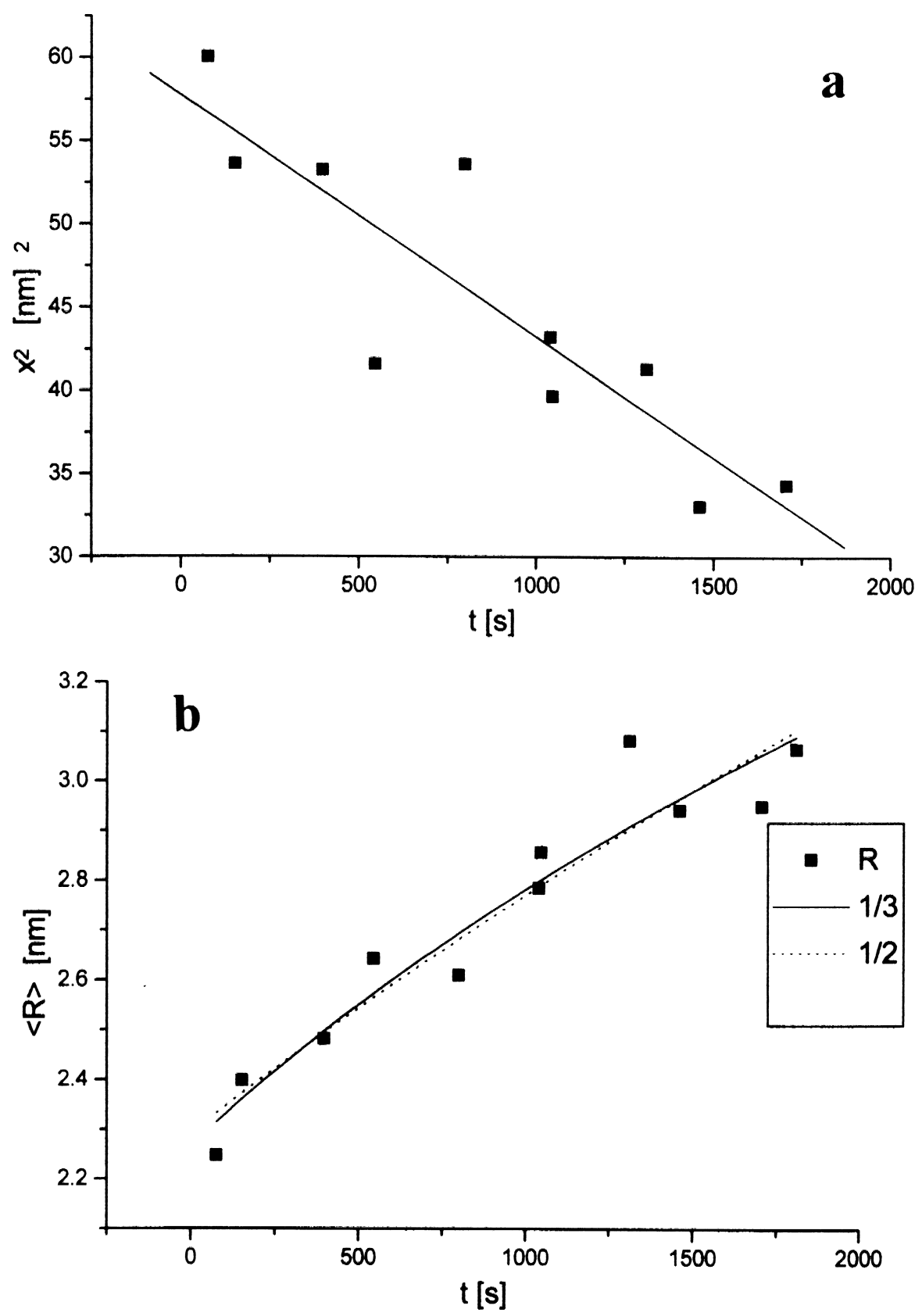

Fig. 8. $x^{2}$ vs $t$ plot (a) and $\langle R\rangle$ vs $t$ plot (b) for a single pit from the 1-dodecanethiol adlayer on $\mathrm{Au}(111)$ starting from thiol addition to the substrate $(t=0)$.

adsorbate-covered domains including adsorbate-covered pits. Coupling surface relaxation processes taking place at these domains including pits lead to a change in the overall adlayer topology.

From wettability and ellipsometry [50], quartz balance [51] and NEXAFS [52] data, the adsorption of alkanethiol molecules from diluted solutions on $\mathrm{Au}(111)$ has been interpreted in terms of an initially fast adsorption process yielding a disordered adlayer followed by a slow reorganization of the disordered adlayer into an ordered adlayer. More recently, STM data resulting from UHV conditions [51] have provided evidence that thiol molecules are adsorbed first with their axis oriented parallel to the surface, reorienting themselves subsequently to adopt their final $(\sqrt{3} \times \sqrt{3}) \mathrm{R} 30^{\circ}$ lattice configuration with their molecu- 

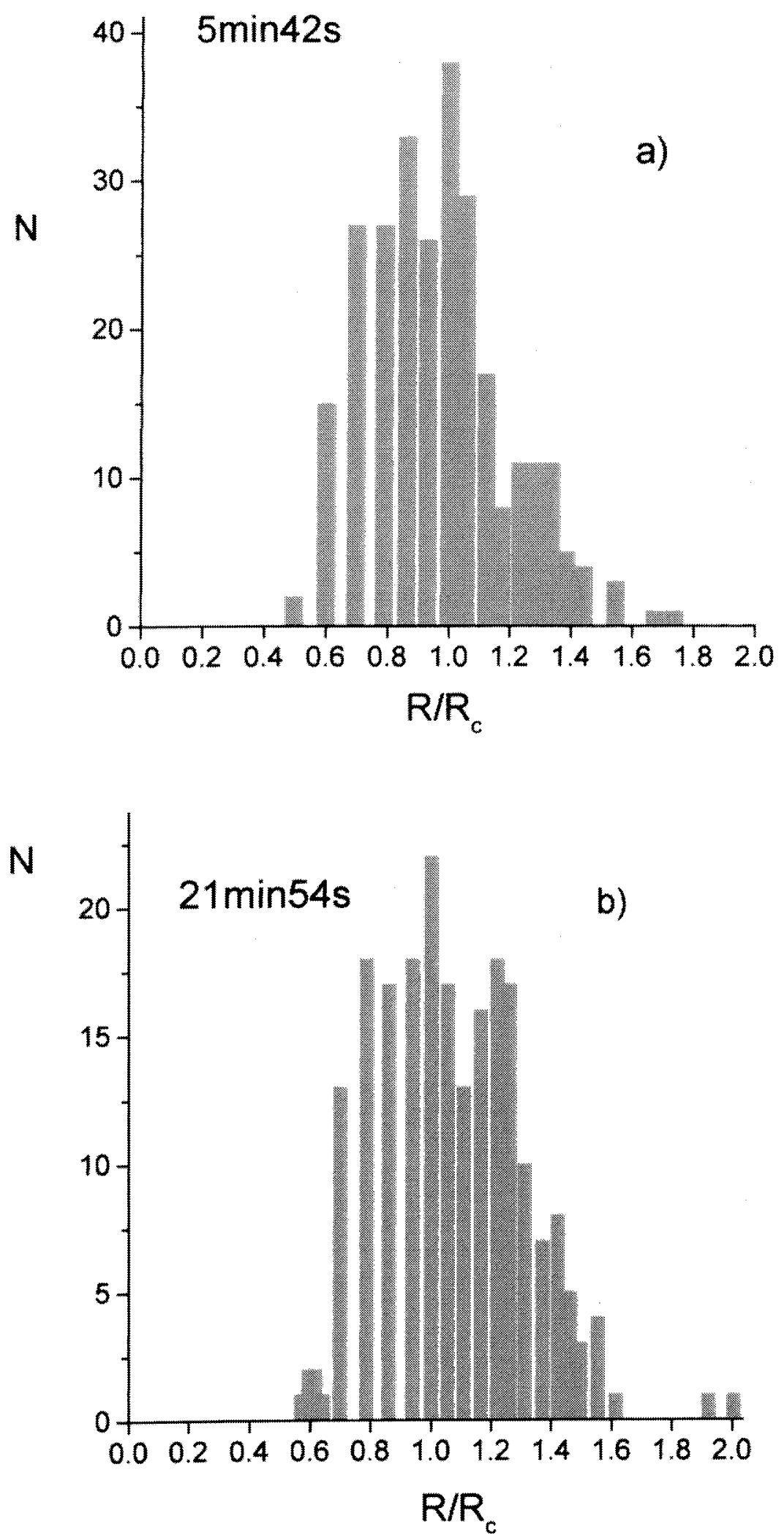

Fig. 9. Pit size distribution (histograms) for $t=5 \operatorname{min~} 42 \mathrm{~s}$ (a), and $t=21 \min 54 \mathrm{~s} \mathrm{(b).}$ 
lar axis tilted about $30^{\circ}$ with respect to the surface normal, although in this case no resolution of the alkyl chains has been shown.

Our results from STM imaging of 1-dodecanethiol adsorption from the pure liquid on $\mathrm{Au}(111)$ are consistent with the following processes. Firstly, a disordered thiol adlayer is formed with the immediate occurrence of surface relaxation processes which can be seen, for instance, by changes in pit shape, size, location and distribution, depending on the time elapsed. Secondly, ordered adlayer domains are progressively produced in which the adsorbed molecules are located at energetically favorable three-fold hollow sites with hcp stacking, although a minor number of adsorbed molecules adopting the three-fold hollow sites with fcc stacking thereby originating the $\mathrm{p}(6 \times 1)$ pattern can also be observed. Although no bonding energy difference data between hollow sites with different stacking sequences are available, the bonding energy ratio of these structures might be reflected by the ratio of the 4 (dark) $\times 2$ (bright) spots of adsorbed molecules shown in Fig. 2.

On the other hand, the $\mathrm{p}(6 \times 1)$ superlattice observed first subsequently changes into the $(\sqrt{3} \times \sqrt{3}) \mathrm{R} 30^{\circ}$ structure (Fig. 4). This rearrangement would indicate that thiol molecules are first adsorbed in hollow sites with a mixed stacking sequence, and then molecules on fcc sites move towards the most favorable hep sites. Further adlayer rearrangements take place after $1-3 \mathrm{~h}$ eventually leading to an adlayer with a structure similar to that of those adlayers obtained from a thiolcontaining solution. It should be noted that a strongly eroded surface after leaving the gold substrate in contact with liquid thiol for $24 \mathrm{~h}$ has been observed [18], but this erosion effect was not observed at least for the duration of our experiments.

\subsection{Single pit diffusion}

The dynamics of pits at the 1-dodecanethiol-monolayer-covered $\mathrm{Au}(111)$ involves single pit diffusion followed by pit coalescence at either terraces or steps edges, and changes in the shape, size and distribution of pits. To help understand whether a single or different mechanisms are involved in these processes, let us first consider the surface diffusion of a single pit. Surface displacement of pits should imply the simultaneous participation of $\mathrm{Au}$ surface atoms and adsorbed 1-dodecanethiol molecules in that event.

The surface diffusion coefficient for $\mathrm{Au}$ atoms either in UHV conditions or in air is $D_{\mathrm{s}}(\mathrm{Au}) \sim 10^{-15} \mathrm{~cm}^{2} /$ $\mathrm{s}[53,54]$, a figure which is somewhat smaller than that found for surface $\mathrm{Au}$ atoms in contact with aqueous acids [55]. The increase in Au surface atom mobility produced by sulphate and chloride [56,57] adsorbates has been attributed to a reduction in the bond strength among neighboring Au atoms caused by the presence of those adlayers. Otherwise, values in the range of $1 \times 10^{-15} \mathrm{~cm}^{2} / \mathrm{s} \leq D_{\mathrm{s}}($ AuTh $) \leq 3 \times 10^{-15} \mathrm{~cm}^{2} / \mathrm{s}$ for the surface diffusion coefficient of thiol adsorbates induced by tip scanning have been reported [17], although, in contrast to these results, a decrease of about two orders of magnitude in the value of $D_{\mathrm{s}}(\mathrm{Au})$ in the presence of $\mathrm{CH}_{3} \mathrm{O}_{2} \mathrm{C}\left(\mathrm{CH}_{2}\right)_{15} \mathrm{SH}$ adsorbates has also been determined [16].

From the preceding results, it can be concluded that the actual surface mass transport at the 1-dodecanethiol-covered $\mathrm{Au}(111)$ interface probably involves a gold atom + thiol adsorbate diffusing entity resulting from a consortial contribution of the rather strong substrate-adsorbate bonding and the lateral alkyl chain interactions in the adsorbate originating a true energy barrier to surface diffusion. Both contributions outweigh the reduction in the bond strength of neighboring $\mathrm{Au}$ atoms due to the alkanethiol chemisorption which would produce an increase in surface atom mobility. Therefore, the decrease in the value of $D_{\mathrm{s}}(\mathrm{Au})$ for 1-dodecanethiol adsorbed on $\mathrm{Au}(111)$ can also be attributed to lateral interactions between alkyl chains of adsorbed molecules. As far as this effect is concerned, a comparison between the alkyl chain of 1dodecanethiol and that of $\mathrm{CH}_{3} \mathrm{O}_{2} \mathrm{C}\left(\mathrm{CH}_{2}\right)_{15} \mathrm{SH}$ adsorbates is useful. In fact, the alkyl chain of 1-dodecanethiol is somewhat shorter than that of $\mathrm{CH}_{3} \mathrm{O}_{2} \mathrm{C}\left(\mathrm{CH}_{2}\right)_{15} \mathrm{SH}$, then a weaker lateral interaction for 1-dodecanethiol as compared to that of $\mathrm{CH}_{3} \mathrm{O}_{2} \mathrm{C}\left(\mathrm{CH}_{2}\right)_{15} \mathrm{SH}$ should be expected. Accordingly, a slightly higher value of $D_{\mathrm{s}}(\mathrm{Au})$ for 1-dodecanethiol than that for $\mathrm{CH}_{3} \mathrm{O}_{2} \mathrm{C}\left(\mathrm{CH}_{2}\right)_{15} \mathrm{SH}$ on $\mathrm{Au}(111)$ should be observed. Then, it would be appropriate to attempt an explanation of this difference in the values of $D_{\mathrm{s}}(\mathrm{Au})$ considering the influence of the alkyl chain interaction energy in the activation energy for surface diffusion of both adsorbates at $\mathrm{Au}(111)$.

For alkanethiol monolayers on $\mathrm{Au}(111)$ the alkyl chain interaction energy increases proportionally to the chain length of the molecule at ca. $4.6 \mathrm{~kJ} / \mathrm{mol}$ per methylene unit [28] yielding for the packing energy of 1-dodecanethiol on $\mathrm{Au}(111)$, the value $\Delta E_{1}=59.2 \mathrm{~kJ} /$ mol. From this figure and the heat of fusion of 1-dodecanethiol taken as that of dodecane, $\Delta E_{2}=36.5 \mathrm{~kJ} /$ mol [58], the energy increase $\Delta E=22.7 \mathrm{~kJ} / \mathrm{mol}$ should be reflected as an increase in the activation energy for surface diffusion at the thiol adlayer due to alkyl chain interactions.

On the other hand, the activation energy for bare Au surface diffusion is $\Delta E^{*}(\mathrm{~s}, \mathrm{Au}) \cong 50 \mathrm{~kJ} / \mathrm{mol}$ [28]. However, neglecting alkyl chain interactions, the value of $\Delta E^{*}(\mathrm{~s}, \mathrm{AuTh})$, the activation energy for surface diffusion at 1-dodecanethiol-covered $\mathrm{Au}(111)$ should be about $15 \%$ lower than $\Delta E^{*}$ (s, Au) because of the interlayer relaxation in the $\mathrm{Au}$ (111) lattice caused 
by the presence of the thiol adlayer. Then, taking into account the alkyl chain interactions, the actual value of $\Delta E^{*}(\mathrm{~s}, \mathrm{AuTh}) \cong 65.2 \mathrm{~kJ} / \mathrm{mol}$ is obtained. The difference between the values of $\Delta E^{*}(\mathrm{~s}, \mathrm{Au})$ and $\Delta E^{*}(\mathrm{~s}, \mathrm{AuTh})$ considering gold lattice relaxation and alkyl chain interactions should produce a decrease by a factor between two and three orders of magnitude in $D_{\mathrm{s}}(\mathrm{Au})$ in the presence of the 1-dodecanethiol monolayer, as found in this work: $D_{\mathrm{s}}(\mathrm{AuTh}) \cong$ $(3 \pm 2) \times 10^{-17} \mathrm{~cm}^{2} / \mathrm{s}$. In fact, this figure is of the same order of magnitude as $D_{\mathrm{s}}(\mathrm{Au})$ for hexadecanethiolcovered $\mathrm{Au}(111)$ [28].

\subsubsection{The likely mechanism for pit coalescence}

The change in pit size (Figs. 1 and 5) can be explained in terms of an Ostwald ripening and dynamic coalescence processes [49]. Ostwald ripening implies the increase in pit size at the expense of smaller pits which finally disappear [59]. In contrast to static coalescence, in which pits are immobile and coalesce when their perimeter lines grow together, dynamic coalescence involves pit mobility merging together. These processes imply a decrease in the surface free energy by decreasing the interface area.

The origin of Ostwald ripening and coalescence phenomena is the dependence of $c(R)$, the vacancy (pit) concentration at the surface, on $R$, the pit radius, given by the Gibbs-Thompson equation

$c(R)=c_{\infty} \exp \left[2 \gamma v_{\mathrm{M}} / R k T\right]$,

where $c_{\infty}$ is the concentration of pits with $R>R_{\mathrm{c}}, \gamma$ is the substrate surface tension, $v_{\mathrm{M}}$ is the atomic volume of the diffusing entity, $k$ is the Boltzmann constant, and $T$ is the absolute temperature. Then, depending on the value of $R$, a pit concentration gradient which becomes the driving force of the processes is established.

Equations emerging from the clustering theory [49] provide the time dependence of $R_{\mathrm{c}}(t)$, the critical radius of the mobile entity,

$$
\left\langle R_{\mathrm{c}}(t)\right\rangle=R(0)\left[1+t / \tau_{\mathrm{c}}\right]^{1 /(m+2)} .
$$

where $\tau_{\mathrm{c}}$ is the time constant for clustering, and $m$ is the dimensional exponent in ripening which provides an indication of the rate determining step of the process. For late stage cluster growth at 2D islands [49] in which a 1D surface cluster dimension is involved under mass transport control by either diffusion or interface transfer, the following mechanistic conclusion can be derived from Eq. (3). When $m=0(x=1 / 2)$, the rate process can be related either to a nonsteady state surface diffusion or interface transfer, whereas when $m=1 \quad(x=1 / 3)$, coalescence is governed by steadystate surface diffusion.
Following a conventional curve fitting procedure of the $\langle R\rangle$ vs $t$ data (Fig. 8b), it is difficult to ascertain the most likely value of $m$. This situation can be overcome considering the pit size distribution function data. According to clustering theory [49], the shape of the distribution function depends on the value of $m$. Thus, for $m=0$ it follows that $\left(R / R_{\mathrm{c}}\right)_{\mathrm{M}}=1$, $w_{1 / 2}=0.9$, and $\left(R / R_{\mathrm{c}}\right)_{\mathrm{lim}} \leq 2$; for $m=1, \quad\left(R / R_{\mathrm{c}}\right)_{\mathrm{M}}=$ $1.13, \quad w_{1 / 2}=0.5$, and $\left(R / R_{\mathrm{c}}\right)_{\lim } \leq 1.5$. Accordingly, when these figures are compared to experimental data (Section 3.3), it results that the theoretical mechanisms derived for $m=0$ are applicable to our system, i.e. the overall dynamics at the 1-dodecanethiol-monolayercovered $\mathrm{Au}(111)$ is related to a mechanism involving either surface diffusion under nonsteady state or interface transfer as rate determining.

\subsubsection{Comparison of coalescence data}

The mobility of $\mathrm{Au}$ atoms modified by the alkanethiol adlayer induced by heating has been followed through the change in size of pits at the adlayer $[60,61]$. In this case, $\langle R\rangle$, the average radius of pits, changed with $t_{h}$, the heating time, according to $\langle R\rangle^{2} \sim t_{\mathrm{h}}$, and the increase in pit area was accompanied by a decrease in the number of pits. Then, the overall process implied the transport of vacancies from smaller to larger pits (Ostwald ripening) followed by pit coalescence. In this case, the value $m=0$ can be derived from these experiments, and the overall process has been interpreted in terms of a rate-determining step involving the adsorption-desorption of monovacancies at pit edges. Our results indicate that this mechanism which is confirmed, in principle, can be extended to the dynamics of the alkanethiolmonolayer-covered Au(111) under isothermal conditions.

\section{Conclusions}

SAM monolayers of 1-dodecanethiol on $\mathrm{Au}(111)$ terraces at $298 \mathrm{~K}$ initially constitute a heterogeneous surface consisting of disordered and ordered adsorbate domains at terraces, step edges and pits.

Disordered adsorbate structures evolve forming first a $\mathrm{p}(6 \times 1)$ superlattice structure which then changes to the seemingly most stable $(\sqrt{3} \times \sqrt{3}) \mathrm{R} 30^{\circ}$ structure. At sufficiently long times the $\mathrm{c}(4 \times 2)$ structure was also imaged.

The heterogeneous surface dynamics involves the coalescence and Ostwald ripening phenomena at pits occurring simultaneously with adsorbate ordering at different surface domains indicating that the global process implies a common material flux mechanism. 
The dynamics of pits implies terrace-to-step edge pit diffusion, pit coalescence at both terraces and step edges, and changes in pit size, shape and distribution.

The surface diffusion coefficient of the mobile entity, $D_{\mathrm{s}}(\mathrm{AuTh})=(3 \pm 2) \times 10^{-17} \mathrm{~cm}^{2} / \mathrm{s}$, resulting from experimental data, is about two orders of magnitude smaller than that reported for $\mathrm{Au}(111)$ surface atoms in the absence of adsorbed thiol molecules, $D_{\mathrm{s}}(\mathrm{Au}) \cong 10^{-15} \mathrm{~cm}^{2} / \mathrm{s}$. This difference in surface mobility can be explained in terms of the nature of the surface diffusing species involved in each case (gold thiolate and gold atom, respectively) and the contribution of alkyl chain interactions.

Data analysis in terms of the clustering theory allowed us to conclude that a single mechanism is likely comprised in the overall surface relaxation phenomena in which the mass transport is either a nonsteady state surface diffusion or an interface transfer along step edges as rate-determining step.

\section{Acknowledgements}

This work was financially supported by the Consejo Nacional de Investigaciones Científicas y Técnicas (CONICET) of Argentina and the Comisión de Investigaciones Científicas (CIC) of Buenos Aires Province. M.E.V. is a Member of the Researcher Career (CIC).

\section{References}

[1] L.H. Dubois, R.G. Nuzzo, Ann. Rev. Phys. Chem. 43 (1992) 437.

[2] R. Heinz, J.P. Rabe, Langmuir 11 (1995) 506 and references therein.

[3] B. Parker, A.J. Gellman, Surf. Sci. 292 (1993) 223.

[4] A. Ulman, An Introduction to Ultrathin Organic Films, from Langmuir Blodgett to Self-Assembly, Academic Press, San Diego, 1991.

[5] J.D. Swalen, D.L. Allara, J.D. Andrade, E.A. Chandross, S. Garoff, J. Israelachvili, T.J. McCarthy, R. Murray, R.F. Pease, J.F. Rabolt, K.J. Wynne, H. Yu, Langmuir 3 (1987) 932.

[6] C.D. Bain, G.M. Whitesides, J. Am. Chem. Soc. 111 (1989) 7164.

[7] M.D. Porter, T.B. Bright, D.L. Allara, C.E.D. Chidsey, J. Am. Chem. Soc. 109 (1987) 3559.

[8] R.G. Nuzzo, F.A. Fusco, D.L. Allara, J. Am. Chem. Soc. 109 (1987) 2358.

[9] R.G. Nuzzo, D.L. Allara, J. Am. Chem. Soc. 105 (1983) 4481.

[10] P. Fenter, P. Eisenberger, K.S. Liang, Phys. Rev. Lett. 70 (1993) 2447.

[11] C.E. Chidsey, G.H. Liu, P. Rowntree, G.J. Scoles, Chem. Phys. 91 (1989) 4421.
[12] M. Buck, M. Grunze, F. Eisert, J. Fisher, F. Träger, J. Vac. Sci. Technol. A10 (1992) 926.

[13] C.A. Alves, E.L. Smith, M.D. Porter, J. Am. Chem. Soc. 114 (1992) 1222.

[14] H. Rieley, H.J. Price, R.G. White, R.I.R. Blyth, A.W Robinson, Surf. Sci. 331 (1995) 189.

[15] A. Badia, L. Demers, L. Dickingson, F.G. Morin, R.B. Lennox, L. Reven, J. Am. Chem. Soc. 119 (1997) 11104.

[16] O. Chailapakul, L. Sun, C. Xu, R.M. Crooks, J. Am. Chem. Soc. 115 (1993) 12459.

[17] G.E. Poirier, M.J. Tarlov, Langmuir 10 (1994) 2853.

[18] J.A.M. Sondag-Huethorst, C. Schönengerger, L.G.J. Fokkink, J. Phys. Chem. 98 (1994) 6826.

[19] Y.T. Kim, R.L. McCarley, A.J. Bard, Langmuir 9 (1993) 1941.

[20] F. Terán Arce, M.E. Vela, R.C. Salvarezza, A.J. Arvia, Surf. Rev. Lett. 4 (1997) 637.

[21] N. Camilone III., C.E. Chidsey, G.Y. Liu, T.M. Putvinski, G. Scoles, J. Chem. Phys. 94 (1991) 8493.

[22] H. Sellers, A. Ulman, Y. Shnidman, J.E. Eilers, J. Am. Chem. Soc. 115 (1993) 9389.

[23] R.G. Nuzzo, B.R. Zegarski, L.H. Dubois, J. Am. Chem. Soc. 109 (1987) 733.

[24] M.S. Yenganeh, S.M. Dougal, R.S. Polizzotti, P. Rabinowitz, Phys. Rev. Lett. 74 (1995) 1811.

[25] C. Schönengerger, J.A.M. Sondag-Huethorst, J. Jorritsma, L.G.J. Fokkink, Langmuir 10 (1994) 611.

[26] K. Edinger, A. Golzhäuser, K. Demota, Ch. Wöll, M. Grunze, Langmuir 9 (1993) 4.

[27] C.A. McDermott, M.T. McDermott, J.B. Green, M.D. Porter, J. Phys. Chem. 99 (1995) 13257.

[28] G.E. Poirier, Langmuir 13 (1997) 2019.

[29] S.J. Stranick, A.N. Parikh, D.L. Allara, P.S. Weiss, J. Phys. Chem. 98 (1994) 11136.

[30] R.L. McCarley, O.J. Dunaway, R.J. Willicut, Langmuir 9 (1993) 2775.

[31] E. Delamarche, B. Michel, Ch. Gerber, D. Anselmetti, H.J. Güntherodt, H. Wolf, H. Ringsdorf, Langmuir 10 (1994) 2869

[32] D. Anselmetti, A. Baratoff, H.J. Güntherodt, E. Delamarche, B. Michel, Ch. Gerber, H. Kang, H. Wolf, H. Ringsdorf, Europhys. Lett. 27 (1994) 365.

[33] P. Fenter, A. Eberhardt, P. Eisenberger, Science 266 (1994) 1216.

[34] F. Terán Arce, M.E. Vela, R.C. Salvarezza and A.J. Arvia, J. Chem. Phys. in press.

[35] I. Touzov, C.B. Gorman, J. Phys. Chem. B 101 (1997) 5263.

[36] J. Kang, P.A. Rowntree, Langmuir 12 (1996) 2813.

[37] L.H. Dubois, B.R. Zegarski, R. G Nuzzo, J. Chem. Phys. 98 (1993) 678.

[38] D.M. Kolb, A.S. Dakkouri and N. Batina, in: A.A. Gewirth, H. Siegenthaler (Eds.), Nanoscale Probes of the Solid/Liquid Interface, NATO ASI Series E288, Kluwer, Dordrecht, 1995.

[39] Y.K. Kim, A.J. Bard, Langmuir 8 (1992) 1096.

[40] Y.K. Kim, A.J. Bard, Langmuir 8 (1992) 1102.

[41] K.D. Truong, P.A. Rowntree, J. Phys. Chem. 100 (1996) 19917.

[42] H. Honbo, S. Sugawara, K. Itaya, Anal. Chem. 62 (1990) 272. 
[43] A.R. Sandy, S.G.J. Mochrie, D.M. Zehner, K.G. Huang, D. Gibbs, Phys. Rev. B43 (1991) 4667.

[44] C. Schönengerger, J. Jorritsma, J.A.M. SondagHuethorst, L.G.J. Fokkink, J. Phys. Chem. 99 (1995) 3259.

[45] C.A. Widrig, C.A. Alves, M.D. Porter, J. Am. Chem. Soc. 113 (1991) 2807.

[46] C.A. Alves, E.L. Smith, M.D. Porter, J. Am. Chem. Soc. 114 (1992) 1222

[47] G. Liu, M. Salmeron, Langmuir 10 (1994) 367.

[48] A. Lio, C. Morant, D.F. Ogletree, M. Salmeron, J. Phys. Chem. B 101 (1997) 4767.

[49] M. Zinke-Allmang, L. Feldman, M.H. Grabow, Surf. Sci. Rep. 16 (1992) 377.

[50] C.D. Bain, E.B. Troughton, Y.T. Tao, J. Evall, G.M. Whitesides, R.G. Nuzzo, J. Am. Chem. Soc. 111 (1989) 321.

[51] W. Pan, C.J. Durning, N.J. Turro, Langmuir 12 (1996) 4469.
[52] G. Hähner, Ch. Wöll, M. Buck, M. Grunze, Langmuir 9 (1993) 1955.

[53] H.P. Bonzel, in: J.M. Blakely (Ed.), Surface Physics of Materials, Academic Press, New York, 1975, p. 280

[54] T. Lin, Y. Chun, Surf. Sci. 207 (1989) 539.

[55] C. Alonso, R.C. Salvarezza, J.M. Vara, A.J. Arvia, Electrochim. Acta 35 (1990) 1131.

[56] D.J. Trevor, C.E.D. Chidsey, D.N. Loiacono, Phys. Rev. Lett. 62 (1989) 929.

[57] D.J. Trevor, C.E.D. Chidsey, J. Vac. Sci. Technol. B 9 (1991) 964.

[58] Handbook of Chemistry and Physics, 76th ed., CRC Press, New York, 1970, p. C670.

[59] A.W. Adamson, Physical Chemistry of Surfaces, WileyInterscience, New York, 1990.

[60] O. Cavalleri, A. Hirstein, K. Kern, Surf. Sci. 340 (1995) L960.

[61] J.P. Bucher, L. Santesson, K. Kern, Langmuir 10 (1994) 979. 